\title{
Root-to-Shoot Communication to Modulate Source-Sink Relationship in Tomato Depends on Phytochromes
}

\author{
Valéria Cury Galati ${ }^{1}$, Reginaldo de Oliveira ${ }^{1}$, Lucas Aparecido Gaion ${ }^{1}$, Vanessa Cury Galati ${ }^{2}$ \\ \& Rogério Falleiros Carvalho ${ }^{1}$ \\ ${ }^{1}$ Department of Biology Applied to Agriculture, São Paulo State University, Brazil \\ ${ }^{2}$ Centro Universitário de Votuporanga (UNIFEV), Votuporanga, SP, Brazil \\ Correspondence: Rogério Falleiros Carvalho, Department of Biology Applied to Agriculture, São Paulo State \\ University, Via de Acesso Prof. Paulo Donato Castellane s/n, 14884-900, Brazil. Tel: 55-16-997-796-442. E-mail: \\ rogerio.f.carvalho@unesp.br
}

Received: April 26, 2018

Accepted: May 28, $2018 \quad$ Online Published: July 15, 2018

doi:10.5539/jas.v10n8p174

URL: https://doi.org/10.5539/jas.v10n8p174

\begin{abstract}
Phytochromes have been reported as strategic photoreceptors that can modulate the partition of photoassimilates between source and sink. However, so far, it is unknown whether phytochrome accumulation in the root is part of the control mechanisms of the source-sink relationship that modulates root and shoot growth. Thus, the objective of this work was to investigate phytochrome involvement in the source-sink relationship and in the vegetative and reproductive development of tomato plants (Solanum lycopersicum L. cv. Micro-Tom or MT). The experimental design was completely randomized with four treatments, provided by grafting combinations between aurea (au), which is phytochrome deficient, and the near isogenic line MT: (MT/MT, au/au, MT/au and $a u / \mathrm{MT})$. We observed differentiated responses for many parameters analyzed. For example, the root dry mass accumulation and stern diameter obtained by MT/MT, MT/au and au/MT grafting were $33 \%$ and $31 \%$ higher, respectively, than those obtained by $a u / a u$. In the $a u / \mathrm{MT}$ combination, there were greater root dry mass and total dry mass accumulations. Based on the changes in vegetative and reproductive development observed from grafting combinations between MT and the mutant $a u$, we can conclude that phytochromes function in the control of photoassimilate partitioning between roots and stems during tomato growth.
\end{abstract}

Keywords: grafting, photoassimilates, photoreceptors, long-distance signalization

\section{Introduction}

Plant development is strongly influenced by countless internal and external factors, such as the intensity and quality of red light; far-red ratios are signals that modulate the photoassimilate transport dynamics (Bocallandro et al., 2003; Tang \& Liesche, 2017). However, this is dependent on the perception of light by specialized photoreceptors called phytochromes, which are part of a complex signal transduction network responsible for coordinating plant development in response to light conditions (Sun et al., 2005; Salisbury et al., 2007; Martínez García et al., 2010). These photoreceptors show two interconvertible relatively stable forms: one that absorbs red (R) light $(\sim 660 \mathrm{~nm})$ and another that absorbs far-red (FR) light $(\sim 730 \mathrm{~nm})$. For instance, under shading conditions, there is a reduction in the R/FR ratio that is perceived by the phytochromes and triggers intricate mechanisms that promote, for example, stem elongation to find better and adequate light conditions (Ballaré; Pierik, 2017; Van Gelderen et al., 2018). In fact, plants deficient in functional phytochromes exhibit exaggerated stem elongation and leaf chlorosis (Muramoto et al., 2005; Carvalho et al., 2011). This occurs mainly because the stem becomes the main sink of the plant and thus reduces the resources available for the development of roots and leaves (Casal, 2013). Currently, it is well known that the mechanisms by which phytochromes modulate the reduction in R/FR light responses involve many intricate molecular pathways in the shoot (Lee et al., 2017; Yang, Xie, Jiang, Z. Li, Huang, \& L. Li, 2018).

Nevertheless, it has only recently been shown that phytochromes can accumulate in roots and modulate plant development (Warnasooriya \& Montgomery, 2011; Costigan, Warnasooriya, Humphries, \& Montgomery, 2011; Júnior et al., 2018; Sakuraba \& Yanagisawa, 2018). However, one question remains: if phytochromes accumulate in the root, do they function in the mechanisms controlling the source-sink relationship that involves root and shoot communication? 
To better understand the factors involved in root-to-shoot signaling, grafting has been an important research tool because molecular and/or biochemical changes, either endogenously or exogenously induced, in the scion can result from modifications in both the root and shoot (Gratão et al., 2015, Gaion et al., 2018). Thus, to study light signaling, especially that phytochrome-dependent, in photoassimilate partition control, it is interesting to associate the grafting technique with molecular tools, such as photomorphogenic mutants.

Therefore, in this work, we demonstrated by grafting that the presence of Micro-Tom functional phytochromes and their combination, as scion or rootstock, in phytochrome-defective aurea mutant modulates the partition and allocation of photoassimilates, especially between roots and stems.

\section{Material and Methods}

\subsection{Plant Material}

Seeds of tomato cv. Micro-Tom (MT) and photomorphogenic mutants deficient in phytochrome aurea (au) (Carvalho et al., 2011) were germinated in plastic trays containing a mixture of Bioplant ${ }^{\circledR}$ substrate and expanded vermiculite in a ratio of $1: 1(\mathrm{v}: \mathrm{v})$, and 15 days after sowing (DAS), seedlings of homogeneous developmental pattern were selected.

\subsection{Grafting and Cultivation}

The grafted plants were obtained by cutting them into a wedge shape and inserting them into a "V"-shaped incision in the rootstock (Peres et al., 2005). A completely randomized design was used with four treatments from combinations between MT and au (MT/au, au/MT, MT/MT and au/au, the first genotype being the graft and the second the rootstock) with three repetitions. After grafting, the plants were transferred to a floating moist chamber, where they remained until 30 DAS, when the complete healing of the grafting region was verified. After this time, the seedlings were transplanted into $1.4 \mathrm{~L}$ pots containing the same substrate for cultivation of the abovementioned seedlings. In addition, supplemental fertilization with $1 \mathrm{~g} \mathrm{~L}^{-1} \mathrm{NPK}$ 10:10:10 was carried out together with $4 \mathrm{~g} \mathrm{~L}^{-1}$ dolomitic limestone. Throughout the experimental period of 65 days (sowing to harvest), the plants were irrigated daily.

\subsection{Parameters Evaluated}

At the end of the experiment, plant growth analyses were performed, such as length, density and root area, by coloring the root system with methylene blue solution for approximately 2 minutes, followed by image recording using a Hewlett Packard digitizer model 5C and processing by Delta-T Scan software. The total leaf area was also obtained by scanning the leaves and subsequent analysis of the images by the Delta-T Devices LTD image analysis system. The length and diameter of the stem were measured using a digital pachymeter, and these measurements were made from the region of stem insertion in the soil. Finally, dry biomass accumulation was also analyzed, for which the root, stem and leaf material were separately packed in paper bags and oven-dried at $55^{\circ} \mathrm{C}$ for 96 hours and weight was measured using a digital analytical balance (Denver Instrument Company AA-200) with an accuracy of $0.0001 \mathrm{~g}$. In addition, the reproductive characteristics, including the number of fruits per plant, fruit diameter (using a digital pachymeter), fruit weight and fruit soluble solids content, were evaluated by means of a digital refractometer (Atago PR-101 Palette, AOAC 1997).

\subsection{Statistical Analyzes}

The results were submitted to analysis of variance (ANOVA) and F test, and when significant, the averages were compared using the Tukey test at 5\% probability using the SISVAR ${ }^{\circledR}$ SOFTWARE (Ferreira, 2011).

\section{Results and Discussion}

\subsection{Root Development}

Regarding root length, the highest values were observed in self-grafted MT/MT plants compared to au/au, MT/au and $a u / \mathrm{MT}$ plants (Table 1). Indeed, the reduction in root growth in au/au and MT/au was expected because the synthesis chromophore of phytochrome in the roots is necessary for its photoregulation. The au mutant is deficient in this biosynthesis; consequently, root growth and development will be impaired (Muramoto et al., 2005; Costigan, Warnasooriya, Humphries, \& Montgomery, 2011; Bianchetti et al., 2017). However, the root length of $a u / \mathrm{MT}$ also decreased when compared to MT/MT.

In addition, the root area was influenced by the type and position of the genotype (Table 1), with more pronounced responses in MT/MT self- and reciprocal MT/au-grafted plants, at $2943.1 \mathrm{~mm}^{2}$ and $4442.1 \mathrm{~mm}^{2}$, respectively, whereas smaller root areas were found in plants in which the genotype of the shoot was deficient in phytochrome [i.e., au/au $\left(2142.3 \mathrm{~mm}^{2}\right)$ and au/MT $\left(2744.2 \mathrm{~mm}^{2}\right)$ ]. These results indicate that the balance of phytochromes present in the roots and shoots is fundamental in determining the longest root length. Furthermore, 
it has been described in several studies that phytochromes located in the shoot are able to modulate the development of the roots by long-distance pathway signals (Salisbury et al., 2007; Zheng et al., 2013; Van Gelderen et al., 2018).

Table 1. Length, density, root area and dry mass of auto-grafting plants of MT and au and their reciprocal combinations $\mathrm{MT} / \mathrm{au}, \mathrm{au} / \mathrm{MT}$

\begin{tabular}{|c|c|c|c|c|}
\hline Combinations & Length of roots & Root density & Root area & Root dry mass \\
\hline & ---------- mm -------- & ------ $\mathrm{mg} \mathrm{cm}^{-3}$ & -------- $\mathrm{mm}^{2}$------- & ------- g plant ${ }^{-1}$------ \\
\hline $\mathrm{MT} / \mathrm{MT}$ & $5681.4 \mathrm{a}$ & $18.38 \mathrm{a}$ & $2943.1 \mathrm{ab}$ & $0.03 \mathrm{a}$ \\
\hline$a u / a u$ & $2957.4 \mathrm{~b}$ & $11.83 \mathrm{~b}$ & $2142.3 \mathrm{~b}$ & $0.02 \mathrm{~b}$ \\
\hline $\mathrm{MT} / \mathrm{au}$ & $3613.9 \mathrm{~b}$ & $14.45 \mathrm{ab}$ & $4442.1 \mathrm{a}$ & $0.03 \mathrm{a}$ \\
\hline$a u / \mathrm{MT}$ & $3071.2 \mathrm{~b}$ & $12.28 \mathrm{~b}$ & $2744.2 \mathrm{~b}$ & $0.03 \mathrm{a}$ \\
\hline Test F & $17.65^{* *}$ & $9.77 * *$ & $8.29 * *$ & $13.69 * *$ \\
\hline CV $(\%)$ & 13.6 & 11.63 & 19.0 & 8.60 \\
\hline
\end{tabular}

Note. CV: coefficient of variation. Means followed by distinct letters in the columns, differ by Tukey test (P $<$ $0.05)$.**; and ns: significant $(\mathrm{P}<0.01)$; and not significant, respectively.

Similarly, root density (Table 1) was significantly higher in the self-grafted MT/MT $\left(18.38 \mathrm{mg} \mathrm{cm}^{-3}\right)$ than in the au/au $\left(11.83 \mathrm{mg} \mathrm{cm}^{-3}\right)$ and $a u / \mathrm{MT}\left(12.28 \mathrm{mg} \mathrm{cm}^{-3}\right)$, but no difference was observed when compared to MT/au $\left(14.45 \mathrm{mg} \mathrm{cm}^{-3}\right)$. In fact, several studies have evidenced the involvement of phytochromes as part of the mechanisms that modulate the production and allocation of photoassimilates from shoots to roots to promote the latter's development (Kasperbauer \& Hunt, 1992; Wang et al., 2016; Tang \& Liesche, 2017).

However, our results demonstrate that, in addition to modulating development, phytochromes act in partitioning and mobilization of photoassimilates to roots, for instance, the accumulation of RDM (root dry mass) obtained in the grafting of MT/MT, MT/au and au/MT was 33\% higher than that in au/au. Therefore, considering the higher accumulation of biomass in $a u / \mathrm{MT}\left(0.03 \mathrm{~g} \mathrm{plant}^{-1}\right)$ than in $\mathrm{au} / \mathrm{au}\left(0.02 \mathrm{~g} \mathrm{plant}^{-1}\right)$, it is possible to infer that the action of phytochromes reflected positively on the root dry mass accumulation.

Thus, we determined that the light signal perceived by the grafting combination that has perfect functional phytochromes in shoots or roots (MT/MT, MT/au and $a u / \mathrm{MT}$ ) was responsible for the greater content of photoassimilates; these photoassimilates produced in shoot were reallocated to roots, favoring root growth mainly from MT/MT and MT/au combinations.

\subsection{Shoot Development and Dry Mass Accumulation and Partitioning}

To better understand the role of root phytochromes in shoot development, biometric analyses were performed measuring the following: stem diameter (SD), stem elongation (SE), leaf area (LF), dry stem mass accumulation (DSMA) and leaf dry mass (LDM) (Table 2). Initially, we observed that SE from MT/MT, MT/au and $a u / M T$ was very similar. On the other hand, when we compared MT/MT stem elongation with the mutant defective in phytochrome self-grafted au/au plants, a 31\% reduction in stem elongation was observed (Table 2). Indeed, it is known that the deficiency in phytochromes present in $a u$ induces greater stem elongation, resulting in diameter reduction (Terry \& Kendrick, 1996; Carvalho et al., 2011), which is consistent with our results (Figure 1).

Thus, SD is an important trait to be evaluated because it is directly related to stem growth and consequently to photoassimilate accumulation in this organ (Casal, 2013). In this direction, what has been observed in this study was as follows: although there was a considerable reduction in au/au SD compared to MT/MT, the SE was not significantly affected (Table 2). Moreover, it is important to note that this parameter was slightly higher in the au/au $(10.80 \mathrm{~cm})$ and $a u /$ MT $(10.0 \mathrm{~cm})$ plants than in MT/MT $(9.89 \mathrm{~cm})$ and MT/au $(9.31 \mathrm{~cm})$. 
Table 2. Stem diameter (SD), stem elongation (SE), leaf area (LF), dry stem biomass accumulation (DSBA) and leaf dry mass (LDM) and total accumulation (DMT) of MT and au autografts and their combinations MT/au, au/MT

\begin{tabular}{|c|c|c|c|c|c|c|}
\hline Combinations & SD & ES & DSBA & LF & LDM & DMT \\
\hline & ----- mm ----- & ----- cm ----- & -- g plant $^{-1}$-- & ----- $\mathrm{cm}^{2}$----- & \multicolumn{2}{|c|}{---------- g plant ${ }^{-1}$--------- } \\
\hline $\mathrm{MT} / \mathrm{MT}$ & $2.81 \mathrm{a}$ & $9.89 \mathrm{a}$ & $0.04 \mathrm{a}$ & $25.63 \mathrm{~b}$ & $0.09 \mathrm{a}$ & $0.16 \mathrm{a}$ \\
\hline$a u / a u$ & $1.95 \mathrm{~b}$ & $10.80 \mathrm{a}$ & $0.03 \mathrm{~b}$ & $19.81 \mathrm{~b}$ & $0.06 \mathrm{~b}$ & $0.11 \mathrm{~b}$ \\
\hline $\mathrm{MT} / \mathrm{au}$ & $2.80 \mathrm{a}$ & $9.31 \mathrm{a}$ & $0.03 \mathrm{~b}$ & $33.37 \mathrm{a}$ & $0.08 \mathrm{ab}$ & $0.14 \mathrm{ab}$ \\
\hline$a u / \mathrm{MT}$ & $2.43 \mathrm{ab}$ & $10.0 \mathrm{a}$ & $0.02 \mathrm{~b}$ & $22.81 \mathrm{~b}$ & $0.08 \mathrm{ab}$ & $0.13 \mathrm{ab}$ \\
\hline Test F & $5.59 *$ & $0.47 \mathrm{~ns}$ & $6.02 *$ & $19.97 * *$ & $4.16^{*}$ & $6.90 *$ \\
\hline $\mathrm{CV}(\%)$ & 11.94 & 15.78 & 21.79 & 8.89 & 12.65 & 10.32 \\
\hline
\end{tabular}

Note. $\mathrm{CV}$; coefficient of variation. Means followed by distinct letters in the columns, differ by Tukey test (P $<$ $0.05)$.**; and ns: significant $(\mathrm{P}<0.01)$; and not significant, respectively.

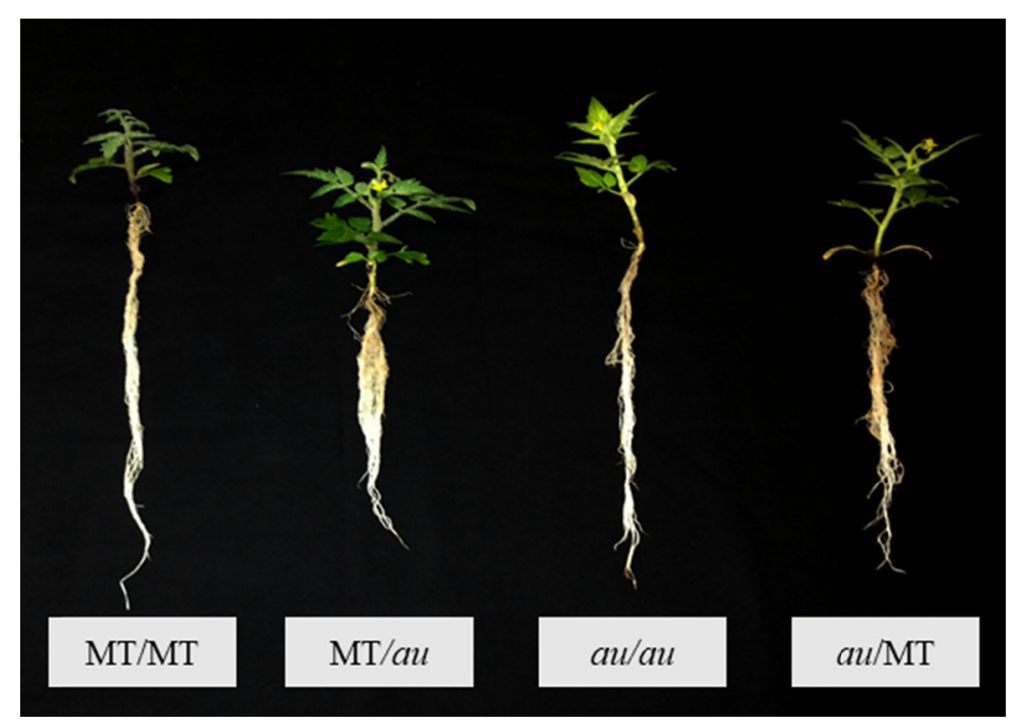

Figure 1. Phenotypic traits of the grafted plants. The first genotype indicates the scion, and the second is the rootstock

On the other hand, the allocation of stem dry biomass in MT/MT was higher than that observed in au/au, MT/au and $a u / \mathrm{MT}$ (Table 2). Consequently, we suggest that this fact is due to the greater photomorphogenic stability of MT/MT compared to other combinations. In fact, phenotypically, MT/MT plants presented larger stem diameters and less elongation. Nonetheless, even when they did not differ significantly, the presence of functional phytochrome in roots $(a u / \mathrm{MT})$ promoted a decrease in SE and increased the SD compared to au/au. These responses are strong evidence that functional root phytochromes are able to regulate the reallocation of photoassimilates in the stem, preventing it from becoming thinner in $a u / \mathrm{MT}$, for example.

On the other hand, in the presence of functional phytochromes in shoots (MT/au), the leaf area is significantly increased when compared to other combinations (Table 2). In fact, phytochromes regulate, in part, the internal division of carbon in leaves and, thus, directly interfere with plant growth (Yanovsky, Casal, Salerno, \& Sanchez, 1995; Melo, Constantino, Cacho, \& Carvalho, 2014). In addition, it is possible that rootstock defective in phytochrome $(a u)$ may require less reserves to roots, carrying greater accumulation on leaves. Interestingly, the accumulations of leaf dry mass and total dry mass were significantly different only among self-grafted plants (Table 2). Thus, the results in MT/MT are greater than 33\% and 31\%, respectively, than those observed in au/au.

It is known that the perception of the light signal through photomorphogenic receptors can influence the distribution of photoassimilates on plants (Yang, Seaton, Krahmer, \& Halliday, 2016; Tang \& Liesche, 2017). Thus, the lack or presence of these receptors can modulate the way the photosynthates are mobilized and allocated in plants. Therefore, the allocated dry biomass to roots and leaves did not differ significantly between the grafting combinations, with values ranging from 16 to $24 \%$ and 56 to $61 \%$ of the total dry mass of the plants, 
respectively (Figure 2). Independent of grafting combinations, MT/MT plants $(\mathrm{F}=4.89, \mathrm{P} \leq 0.05)$ accumulated higher dry biomass in the stem. However, as shown in Figure 2, the stem dry biomass of the au/MT combination was decreased, while the root dry mass increased. Although the dry mass accumulation consistently decreased with phytochrome limitation in the combinations with aurea (MT/au, au/MT and au/au), when present in the roots $(a u / \mathrm{MT})$, this photoreceptor clearly influenced the partition of photoassimilates.

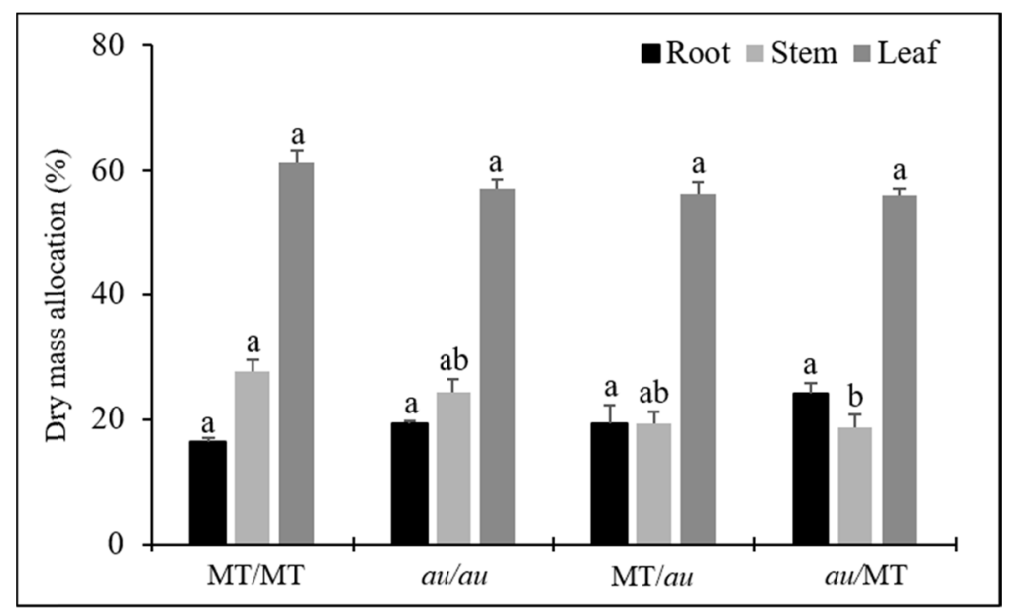

Figure 2. Allocation of photoassimilates (dry mass) in the roots, stem and leaves in relation to the total dry mass of Micro-Tom, MT/MT, and aurea ( $a u / a u)$ autografts and their reciprocal combinations (MT/au, au/MT)

Note. The same lowercase letters in the column do not differ by Tukey's test at $5 \%$ probability. Bars above the column represent the standard error of the averages $(n=3)$.

In other words, the observed results reveal the specific influence of phytochromes on the partition of photoassimilates between root and stem, that is, while root dry mass in $a u / \mathrm{MT}$ increased, the stem dry mass decreased and vice versa. Thus, the mutation of $a u$ present in the $a u / a u$ and $a u /$ MT grafting typically stimulates a greater photoassimilate allocation to the shoot growth, reducing the dry mass of the other parts (roots and leaves). In addition, the above values reinforce the hypothesis of root phytochrome control on photoassimilate partitioning to shoot development, as the dry mass ratio was decreased and root increased in au/MT (Figure 1). However, this event should still be approached in other studies because $a u$ /MT did not differ significantly from au/au and MT/au.

\subsection{Reproductive Parameters}

The reproductive characteristics presented in Table 3 clearly demonstrate that fruit shape and quality were influenced by the combinations of grafting. In this way, the diameter of the fruits resulting from the reciprocal grafted plants (i.e., MT/au and $a u / \mathrm{MT}$ ) increased by $7 \%$ in relation to the self-grafted $a u / a u$ and MT/MT plants. Similarly, the fresh fruit weights of $a u / \mathrm{MT}\left(4.88 \mathrm{~g} \mathrm{plant}^{-1}\right)$ and MT/au $\left(4.19 \mathrm{~g} \mathrm{plant}^{-1}\right)$ were higher than those of MT/MT (3.73 g plant $\left.{ }^{-1}\right)$ and au/au $\left(3.81 \mathrm{~g} \mathrm{plant}^{-1}\right)$. However, the abovementioned significant increases (diameter and fruit weight) in $a u / \mathrm{MT}$ and MT/au were accompanied by a mean reduction of $3 \%$ in soluble solids content in relation to self-grafted MT/MT and au/au. Thus, we have noted that fruit growth occurred at the expense of soluble solids content. Interestingly, the soluble solids contents between MT/MT and au/au did not differ. According to Melo et al. (2014), the au mutant presents a high capacity for remobilization of photoassimilates during the reproductive stage, prioritizing the fruits. 
Table 3. Total fruit, fruit diameter, fresh fruit weight and soluble solids contents in the fruits of the auto-grafting $\mathrm{MT}$ and $a u$ and their combinations MT/au, au/MT

\begin{tabular}{lllll}
\hline Combinations & Total fruits & Diameter of fruit & Fruit weight & Soluble solids content \\
\hline & Numbers & $\mathrm{cm}$ & $\mathrm{g} \mathrm{planta}^{-1}$ & ${ }^{\circ}$ Brix \\
MT/MT & $4.0 \mathrm{a}$ & $1.96 \mathrm{~b}$ & $3.73 \mathrm{~b}$ & $4.94 \mathrm{a}$ \\
au/au & $3.0 \mathrm{a}$ & $1.97 \mathrm{~b}$ & $3.81 \mathrm{~b}$ & $4.92 \mathrm{a}$ \\
MT/au & $5.0 \mathrm{a}$ & $2.11 \mathrm{a}$ & $4.19 \mathrm{ab}$ & $4.78 \mathrm{~b}$ \\
au/MT & $3.0 \mathrm{a}$ & $2.12 \mathrm{a}$ & $4.88 \mathrm{a}$ & $4.76 \mathrm{~b}$ \\
\hline Test F & $1.6 \mathrm{~ns}$ & $14.43^{* *}$ & $5.49^{*}$ & $22.72^{* *}$ \\
CV $(\%)$ & 30.0 & 1.94 & 9.31 & 0.95
\end{tabular}

Note. $\mathrm{CV}$; coefficient of variation. Means followed by distinct letters in the columns, differ by Tukey test (P $<$ $0.05)$. **; and ns: significant $(\mathrm{P}<0.01)$; and not significant, respectively.

In fact, in addition to an inverse relationship between size and soluble solids content, fruits constitute a strong draining organ that demands reserves of other parts of the plant during the reproductive period (Rodrigues et al., 2014; Turhan, Ozmen, Serbeci, \& Seniz, 2011). Therefore, there are many mechanisms involved in the import, metabolism and accumulation of sugars in tomato fruits, influenced directly by a complex signaling pathway between phytochromes and hormones (Gupta et al., 2014; Bianchetti et al., 2017). However, our results indicate that the phytochrome-dependent responses observed in the au mutation are triggers near the reproductive stage, suggesting that they can synthesize some amount of functional phytochrome at this stage, even maintaining its characteristic phenotype with chlorotic leaves throughout the cycle (Sharrock, Parks, Koornneef, \& Quail, 1988; Tuinen et al., 1996; Terry, Ryberg, Raitt, \& Page, 2001).

In summary, our results provide information about the control of the partition of photoassimilates and their relocation of the source organs to the sink, which in part is controlled by phytochromes accumulated in the roots, involving complex morphophysiological differentiation that still needs to be further explored in $a u$ as well as in its grafting combinations with MT.

\section{Conclusion}

Based on the changes in vegetative and reproductive development observed from the grafting combinations between MT and the mutant $a u$, we concluded that phytochromes function in the control of the partition of photoassimilates between roots and stem during the growth of the tomato.

\section{References}

Ballaré, C. L., \& Pierik, R. (2017). The shade-avoidance syndrome: Multiple signals and ecological consequences. Plant, Cell \& Environment, 40(11), 2530-2543. https://doi.org/10.1111/pce.12914

Bianchetti, R. E., Cruz, A. B., Oliveira, B. S., Demarco, D., Purgatto, E., Peres, L. E. P., ... Freschi, L. (2017). Phytochromobilin deficiency impairs sugar metabolism through the regulation of cytokinin and auxin signaling in tomato fruits. Scientific Reports, 7(1), 7822. https://doi.org/10.1038 / s41598-017-08448-2

Boccalandro, H. E., Ploschuk, E. L., Yanovsky, M. J., Sánchez, R. A., Gatz, C., \& Casal, J. J. (2003). Increased phytochrome B alleviates density effects on tuber yield of field potato crops. Plant Physiology, 133(4), 1539-1546. https://doi.org/10.1104/pp.103.029579

Carvalho, R. F., Campos, M. L., Pino, L. E., Crestana, S. L., Zsögön, A., Lima, J. E., ... Peres, L. E. (2011). Convergence of developmental mutants into a single tomato model system: 'Micro-Tom' as an effective toolkit for plant development research. Plant Methods, 7(1), 18. https://doi.org/10.1186/1746-4811-7-18

Casal, J. J. (2013). Photoreceptor signaling networks in plant responses to shade. Annual Review of Plant Biology, 64, 403-427. https://doi.org/10.1146/annurev-arplant-050312-120221

Costigan, S. E., Warnasooriya, S. N., Humphries, B. A., \& Montgomery, B. L. (2011). Root-localized phytochrome chromophore synthesis is required for photoregulation of root elongation and impacts root sensitivity to jasmonic acid in Arabidopsis. Plant Physiology, 157(3), 1138-1150. https://doi.org/10.1104/ pp.111.184689

Ferreira, D. F. (2011). Sisvar: A computer statistical analysis system. Ciência e Agrotecnologia, 35(6), 1039-1042. http://dx.doi.org/10.1590/S1413-70542011000600001 
Flores, F. B., Sanchez-Bel, P., Estan, M. T., Martinez-Rodriguez, M. M., Moyano, E., Morales, B., ... Romojaro, F. (2010). The effectiveness of grafting to improve tomato fruit quality. Scientia Horticulturae, 125(3), 211-217. https://doi.org/10.1016/j.scienta.2010.03.026

Gaion, L. A., Monteiro, C. C., Cruz, F. J. R., Rossatto, D. R., López-Díaz, I., Carrera, E., ... Carvalho, R. F. (2018). Constitutive gibberellin response in grafted tomato modulates root-to-shoot signaling under drought stress. Journal of Plant Physiology, 221, 11-21. https://doi.org/10.1016/j.jplph.2017.12.003

Gratão, P. L., Monteiro, C. C., Tezotto, T., Carvalho, R. F., Alves, L. R., Peters, L. P., \& Azevedo, R. A. (2015). Cadmium stress antioxidant responses and root-to-shoot communication in grafted tomato plants. Biometals, 28(5), 803-816. https://doi.org/10.1007/s10534-015-9867-3

Gupta, S. K., Sharma, S., Santisree, P., Kilambi, H. V., Appenroth, K., Sreelakshmi, Y., \& Sharma, R. (2014). Complex and shifting interactions of phytochromes regulate fruit development in tomato. Plant, Cell \& Environment, 37(7), 1688-1702. https://doi.org/10.1111/pce.12279

Júnior, D. F., Gaion, L. A., Júnior, G. S., Santos, D. M. M., \& Carvalho, R. F. (2018). Drought-induced proline synthesis depends on root-to-shoot communication mediated by light perception. Acta Physiologiae Plantarum, 40(1), 15. https://doi.org/10.1007/s11738-017-2591-6

Kasperbauer, M. J., \& Hunt, P. G. (1992). Root size and shoot/root ratio as influenced by light environment of the shoot. Journal of Plant Nutrition, 15(6-7), 685-697. https://doi.org/10.1080/01904169209364355

Melo, H. C. D., Constantino, E. J., Cacho, R. C., \& Carvalho, R. F. (2014). Photosynthate partitioning and morphoanatomical aspects of photomorphogenic mutants of tomato. Bioscience Journal, 30(2), 447-457

Muramoto, T., Kami, C., Kataoka, H., Iwata, N., Linley, P. J., Mukougawa, K., ... Kohchi, T. (2005). The tomato photomorphogenetic mutant, aurea, is deficient in phytochromobilin synthase for phytochrome chromophore biosynthesis. Plant and Cell Physiology, 46(4), 661-665. https://doi.org/10.1093/pcp/pci062

Peres, L. E., Carvalho, R. F., Zsögön, A., Bermúdez-Zambrano, O. D., Robles, W. G., \& Tavares, S. (2005). Grafting of tomato mutants onto potato rootstocks: an approach to study leaf-derived signaling on tuberization. Plant Science, 169(4), 680-688. https://doi.org/10.1016/j.plantsci.2005.05.017

Rodrigues, G. S. D. O., Negreiros, M. Z. D., Lopes, W. D. A. R., Grangeiro, L. C., \& Lima, J. S. S. D. (2014). Growth and partitioning of assimilates in tomato trees due to the different kinds of mulching. Revista Caatinga, 27(2), 10-17.

Sakuraba, Y., \& Yanagisawa, S. (2018). Light signalling-induced regulation of nutrient acquisition and utilisation in plants. Seminars in Cell \& Developmental Biology. Academic Press. https://doi.org/10.1016/j.semcdb. 2017.12.014

Salisbury, F. J., Hall, A., Grierson, C. S., \& Halliday, K. J. (2007). Phytochrome coordinates Arabidopsis shoot and root development. The Plant Journal, 50(3), 429-438. https://doi.org/10.1111/j.1365-313X.2007. 03059.x

Sharrock, R. A., Parks, B. M., Koornneef, M., \& Quail, P. H. (1988). Molecular analysis of the phytochrome deficiency in an aurea mutant of tomato. Molecular and General Genetics, 213(1), 9-14. https://doi.org/10.1007/BF00333391

Tang, Y. J., \& Liesche, J. (2017). The molecular mechanism of shade avoidance in crops-How data from Arabidopsis can help to identify targets for increasing yield and biomass production. Journal of Integrative Agriculture, 16(6), 1244-1255. https://doi.org/10.1016/S2095-3119(16)61434-X

Terry, M. J., \& Kendrick, R. E. (1996). The aurea and yellow-green-2 mutants of tomato are deficient in phytochrome chromophore synthesis. Journal of Biological Chemistry, 271(35), 21681-21686. https://doi.org/10.1074/jbc.271.35.21681

Terry, M. J., Ryberg, M., Raitt, C. E., \& Page, A. M. (2001). Altered etioplast development in phytochrome chromophore-deficient mutants. Planta, 214(2), 314-325. https://doi.org/10.1007/s004250100624

Tuinen, A., Hanhart, C. J., Kerckhoffs, L. H. J., Nagatani, A., Boylan, M. T., Quail, P. H., ... \& Koornneef, M. (1996). Analysis of phytochrome-deficient yellow-green-2 and aurea mutants of tomato. The Plant Journal, 9(2), 173-182. https://doi.org/10.1046/j.1365-313X.1996.09020173.x

Turhan, A., Ozmen, N., Serbeci, M. S., \& Seniz, V. (2011). Effects of grafting on different rootstocks on tomato fruit yield and quality. Hortic. Sci., 38, 142-149. https://doi.org/10.17221/51/2011-HORTSCI 
Van Gelderen, K., Kang, C., Paalman, R., Keuskamp, D. H., Hayes, S., \& Pierik, R. (2018). Far-red Light Detection in the Shoot Regulates Lateral Root Development through the HY5 Transcription Factor. The Plant Cell, tpc-00771. https://doi.org/10.1105/tpc.17.00771

Wang, L., \& Ruan, Y. L. (2016). Shoot-root carbon allocation, sugar signalling and their coupling with nitrogen uptake and assimilation. Functional Plant Biology, 43(2), 105-113. https://doi.org/10.1071/FP15249

Warnasooriya, S. N., \& Montgomery, B. L. (2011). Spatial-specific regulation of root development by phytochromes in Arabidopsis thaliana. Plant Signaling \& Behavior, 6(12), 2047-2050. https://doi.org/ $10.4161 /$ psb.6.12.18267

Yang, C., Xie, F., Jiang, Y., Li, Z., Huang, X., \& Li, L. (2018). Phytochrome A Negatively Regulates the Shade Avoidance Response by Increasing Auxin/Indole Acidic Acid Protein Stability. Developmental Cell, 44(1), 29-41. https://doi.org/10.1016/j.devcel.2017.11.017

Yang, D., Seaton, D. D., Krahmer, J., \& Halliday, K. J. (2016). Photoreceptor effects on plant biomass, resource allocation, and metabolic state. Proceedings of the National Academy of Sciences, 113(27), 7667-7672. https://doi.org/10.1073/pnas.1601309113

Yanovsky, M. J., Casal, J. J., Salerno, G. L., \& Sanchez, R. A. (1995). Are phytochrome-mediated effects on leaf growth, carbon partitioning and extractable sucrose-phosphatesynthase activity the mere consequence of stem-growthresponses in light-grown mustard? Journal of Experimental Botany, 46(7), 753-757. https://doi.org/10.1093/jxb/46.7.753

Zheng, J., Zhou, J. J., Zhao, J., Zhao, S. Z., Li, G. R., \& Xie, X. Z. (2013). Phytochromes Are Involved in Elongation of Seminal Roots and Accumulation of Dry Substances in Rice Seedlings. Rice Science, 20(2), 88-94. https://doi.org/10.1016/S1672-6308(13)60115-8

\section{Copyrights}

Copyright for this article is retained by the author (s), with first publication rights granted to the journal.

This is an open-access article distributed under the terms and conditions of the Creative Commons Attribution license (http://creativecommons.org/licenses/by/4.0/). 